\title{
International Journal of Education \& the Arts
}

Editors

Tom Barone

Arizona State University, U.S.A

Liora Bresler

University of Illinois at Urbana-Champaign, U.S.A.

http://ijea.asu.edu

ISBN 1529-8094

Volume 6 Number 12

October 19, 2005

From Image to Text: Using Images in the Writing Process

Nancy Andrzejczak

University of California, Riverside

Guy Trainin

University of Nebraska, Lincoln

Monique Poldberg

Lake Elsinore Unified School District, Lake Elsinore, CA

Citation: Andrzejczak, N., Trainin, G., \& Poldberg, M. (2005, October 19).

From image to text: Using images in the writing process. International Journal of

Education \& the Arts, 6 (12). Retrieved [date] from http://ijea.asu.edu/v6n12/

\begin{abstract}
This study looks at the benefits of integrating visual art creation and the writing process. The qualitative inquiry uses student, parent, and teacher interviews coupled with field observation, and artifact analysis. Emergent coding based on grounded theory clearly shows that visual art creation enhances the writing process. Students used more time for thought elaboration, generated strong descriptions, and developed concrete vocabulary. The advantages of using production of art and artwork in the pre-writing process provided a motivational entry point, a way to develop and elaborate on a scene or a narrative. This study shows that the benefits of a rich visual art experience can enhance thought and writing in response to the finished artwork.
\end{abstract}

It is the assertion of this article that students who use visual art as a pre-writing stimulus are composing their ideas both in images and in words. The result of the art creation process allows students the distance to elaborate, add details, and create more coherent text. 
The process of writing is more than putting words on a piece of paper. Effective authors are able to create imagery and to communicate ideas using well-chosen words, phrases, and text structures. Emergent writers struggle with the mechanics of the writing process, i.e., fine motor control for printing legibly, recall of spelling patterns, and the use of syntax and grammar rules. As a result, texts written by young writers tend to be simplistic and formulaic. The artwork facilitates the writing process, resulting in a text that is richer in sensory detail and more intricate than the more traditional writing-first crayon drawingsecond approach.

There is a growing body of evidence pointing to the positive effect of visual arts on reading and writing performance. Art instruction guides students' observations of the world around them. This increased aesthetic perception of natural and manmade phenomena enhances students' sensibilities impacting artwork, writing and observational skills. In their work, Tishman, McGillivray and Palmer (1999) showed that the skills developed while observing and reasoning about art transferred to students' scientific observation skills.

In a previous publication (Trainin, Andrzejczak, \& Poldberg, 2005), we focused on integrating art and literacy in elementary classrooms to benefit students' writing, language, visual art production and art appreciation. The curriculum explicitly linked art-making and writing. Both writing quality and quantity grew as compared with controls and the school district as a whole. Student artistic perception also improved but was still generally low. Achievement gains translated into gains in standardized tests of language and reading.

Some researchers suggest that visual art is beneficial because it serves mainly as a motivational entry-point to reading and writing activities. These activities engage students in texts and reinforce positive behavior (Burger \& Winner, 2000; Ernst, 1994; , 1995). While motivation may be part of the reason for student increased performance, a meta-analysis focusing on the contribution of motivation to achievement found that the actual effect size is very small (Valentine, DuBois, \& Cooper, 2004). This is supported by the work of Gambrell (1993), (Gambrell \& Bales, 1986), and Sadoski (1985) who hypothesized that the use of imagery goes beyond mere engagement.

Eisner (2002) examined the role of arts education in cognitive development. He posits that visual art can serve as medium for capturing ideas and concepts crystallized into visual form. Eisner suggests that the concrete representation of ideas allows for an editing process similar to editing writing. However, it is important to note that Eisner opposes art integration as a way to increase achievement.

In contrast to Eisner's work, Efland (2002) calls for an examination of the interplay between art and other domains. He claims that the visual arts foster metaphor creation, a key facet of critical thinking. These two major thinkers of art-education claim that there are unique advantages to art instruction. Some empirical support for the cognitive benefits of using images emerges from studies by Dyson (1986), Smagorinsky (1993), and Sadoski (1985). Their work provides partially overlapping theories describing the cognitive processes in detail.

Dyson expanded the Vygotskyan ideas that "make-believe play, drawing, and writing can be viewed as different movements in essentially unified process of development of written language" (Vygotsky, 1978). She hypothesized that the development of symbolic representations is aided by images and leads to higher order thinking (Dyson, 1986, 1987, 1988; Vygotsky, 1978). Dyson explored this hypothesis in her study of young students who used a mixed symbol system of visual art, speech and text to communicate their understandings of the world. She theorized that these symbol systems were interwoven. Seen from this perspective visual art-making allows a wider range of expression than is available 
through language alone by linking visual cues to expression, thus providing a concrete reference. The concrete visual image supports the development of higher-order cognitive functions such as writing. The linking path is, therefore, a semiotic connection between artistic and verbal linguistics signs in which the art is a scaffold for linguistic processes.

Smagorinsky (Smagorinsky \& Coppock, 1993, 1994) proposed that the art serves as a "non-linguistic' composing device that assists children in expressing their thoughts. He diverged from Dyson's (1986) developmental perspective claiming that the process was not just a stage. Smagorinsky extended Sigel's (1970) distancing theory and claims that "students step back from their immediate experiences and create a physical or mental object that they could ponder" (Smagorinsky, 1997). Smagorinsky extends his argument to claim that all writers and readers regardless of developmental stage can benefit from using a visual image.

Sadoski and Paivio (1994) hypothesized that increased reading comprehension through imaging is the result of parallel processing. The image allows processing of the same information through a different route, increasing both cognitive engagement and recall.

In the studies presented above, the image was secondary to the literacy processes themselves. The studies did not focus on the quality of artistic representation nor did they include extensive art instruction. The gap between the positions of Efland and Eisner and the empirical evidence is in the potential of robust artistic creation to impact thinking. We suggest that quality visual art instruction as promoted by Eisner and Efland will build cognitive connections to language and provide students with the ability and skills to capture and elaborate on their ideas beyond the use of iconic images.

The preceding quantitative study (Trainin, Andrzejczak, \& Poldberg, 2005) provided a broad picture of the impact of visual art on student writing. These positive results showed "What works?" but not "Why did it work?" Based on the literature and our own observations, we hypothesized that: (a) students find art motivating and engaging, (b) the artistic process impacts aesthetic sensibilities, and (c) students use the art as a writing scaffold. A case study approach allows us to examine this process in a way that the quantitative methodology did not.

This study explores how students create complex cognitive meaning in their painting leading to written expression. The goal was to deconstruct the actual links between robust images and subsequent texts. We focused on two detailed case-studies unraveling the connections between the visual art and writing.

\section{Method}

\section{School Context}

The students attend an Elementary School for the Arts in southern California. It is a rural area fast becoming a suburb of the greater Los Angeles-Orange County urban areas. This study was part of a multi-year research project examining the impact of visual arts strategies on student academic achievement in literacy(Trainin, Andrzejczak, \& Poldberg, 2005). The target school was chosen for a number of reasons: supportive administration, faculty interest, and diverse demographics (68\% Free/reduced lunch, 38\% Hispanic, 55\% Caucasian, $7 \%$ Other). The accountability climate in California complicated the execution of the project. During the first year of research the school had missed its achievement goals for the second year in a row. The school was identified as under-performing with potential high- 
stakes. Despite these somewhat daunting conditions many of the teachers agreed to stay involved with the project, convinced that art integration would augment achievement.

In the school, visual artwork was evident everywhere. Student work was present in offices and surrounding halls. Throughout the school, large murals dominate the landscape. The murals reflect scenes from school-wide productions such as a tornado bearing down on Kansas from the Wizard of $\mathrm{Oz}$ while others display curriculum content such as the missions in California history.

\section{Instructional Context}

The study was based on the Picturing-Writing process, in which students use visual art as part of the pre-writing process. Picturing-Writing originated in the mid-1990's at the University of New Hampshire and was the focus of a number of empirical studies (Olshansky, 1990, 1994, 1995, 1998). The Picturing-Writing curriculum in this study included two discrete units, Weather Poetry and Time of Day. In both units, students were given instruction in creating visual art using crayon resist and watercolor. As part of the lessons, students interacted with rich thematic literature. Literature was selected based on the quality of text and images. After extensive exposure to the visual and verbal texts, students were asked to create their own visual art reflecting unit themes. The students used their visual art to brainstorm ideas for their writing using a graphic organizer. Finally, the finished paintings and graphic organizers were used as writing scaffolds. The final product was a multi-page book containing visual art and text (poetry, narrative, or expository).

\section{Participants}

The students were Jeremy, a seven-year old boy, and Wendy an eight-year old girl. For purposes of this study, teachers were asked to recommend students who were fully engaged in the Picturing-Writing sequence. Both had participated in the study the previous year, which ensured familiarity with the process.

Jeremy is an active if at times over kinesthetic seven-year old boy. He sports shortcropped light brown hair, and is quick to smile and respond. He finds it extremely difficult to sit in his chair for long periods of time, often wiggling or fiddling with objects. Jeremy is an average reader based on teacher evaluation and standardized test scores.

Wendy is an eight-year-old third grade student. She has medium blond hair and often wore braids. She has an intensity about her that indicated her love of learning. During the interview her body language radiated excitement as she awaited the questions. Wendy excels at her schoolwork, taking pride in her achievement. She is the kind of student that teachers often rely upon to perform tasks or help others. Wendy has above average reading achievement based on teacher evaluation and on her test scores.

\section{Data collection}

Both students were observed and interviewed during Picturing-Writing lessons in their respective classrooms. Jeremy was observed three times in the classroom for forty-five minute blocks, while Wendy was observed twice. They were observed during initial instruction, painting, oral discussion of the paintings, and during the writing process. They were both interviewed to gain additional insight into their thinking and uncover their explicit understanding of the impact of image-making on their writing. There were two forty-five minute interviews for each student. Beyond the initial project discussion, the teachers were interviewed once, one hour each. Parent interviews were less than thirty minutes. 
Student interviews were videotaped and followed a semi-structured format. Rapport was established as the interviewer explained her purpose: "I want to learn how you paint and write," followed by general questions on writing and art-making. The interview relied on student portfolios referring directly to students' paintings, graphic organizers and texts. With each selected piece of art questions started with re-contextualizing, e.g., "What were you learning about when you made this painting?" followed by questions about the painting techniques "How did you make this? Why did you make it this way?" Finally questions were asked about the connections between text and art, e.g., "Tell me about why you chose this word? How did you come with the idea to write [specific text]. Questions were kept openended and general, designed to probe into the child's creative process without creating a bias.

In parent and teacher interviews participants were asked to comment on instruction related behaviors of the students. Following the general questions, specific questions inquired about: vocabulary, attitudes towards school, at-home activities (creating art and writing), and interactions with natural phenomena. If the responses were general, e.g., "Jeremy used a lot of new words," a follow up question asked for a specific example noting the occasion and the word choices.

During classroom observations, the observer took notes and audio-taped interactions. The observers sat with the target student as they worked asking questions about their work in real time. All interviews and observations were transcribed and analyzed with field-notes taken during classroom observations. Digital photographs of student artwork as well as copies of Picturing-Writing products, responses to the district writing prompt, and student daily journals excerpts were included in the analysis.

\section{Data Analysis}

Predetermined codes were created based on the literature and anecdotal evidence.

Parallel to the predetermined codes an emergent coding scheme was developed using a grounded theory methodology (Strauss \& Corbin, 1990). Data was triangulated using multiple sources relying on the intersection of observations, interviews, and artifacts. Predetermined codes used three categories: motivation, aesthetic perception, and response to their own work. However, a new theme began to emerge. Children and teachers repeatedly referred to ideas forming and changing during the painting process. Thus, these "while I was doing it" comments emerged as a fourth category. Each category represents different levels of student involvement in art making in the writing process.

Motivational Entry Point. The intrinsic enjoyment of the art making process attracted children into the writing. Jeremy became excited as the teacher transitioned into art making. The art making became the hook into the academic endeavors of writing. Numerous authors have documented how children are motivated to participate in academic activities by the art activity (Burger \& Winner, 2000; Cho, 1996; Winner \& Cooper, 2000; Winner \& Hetland, 2000).

Observation of the world and artwork. Aesthetic perception was also a key area noted in the student and parent interviews. The instruction process heightened awareness of the natural world and stimulated the child's natural curiosity about nature. Students had gained a heightened perception of both natural and man-made phenomena. Both parents reported that their children would routinely comment on colors in the sky, shapes or colors of plants, and so forth. They felt that this perceptual change had occurred when the children were introduced to the process and was increasing over time (Tishman, MacGillivray, \& Palmer, 1999). 
Response to the finished work of art. This is the code used for the student's brainstorming or writing process that happened after the painting was completed. Often this can be likened to finding animals in clouds or ink blots. We found that some children routinely thought of new ideas in response to the finished images that were vastly different than the ideas that they had going into the art making process. At other times the painting would serve as an anchor or focus for the pre-writing process (Dyson, 1986; Olshansky, 1995; Smagorinsky \& Coppock, 1993).

The creative process or "while I was doing the art" This code used for thought processes that occurred during the actual making of the work. As the art developed (at times accidentally) students transformed and extended their ideas. For example, a drip of paint became an octopus and an ocean story emerged.

\section{Results}

Results are presented by coding categories. Both case studies are integrated within each coding category to present a coherent picture of the data. Art and writing artifacts presented here are typical of student performance and were chosen to illustrate with minimal repetition

\section{Motivational entry-point.}

Jeremy: Jeremy's mother reported that Jeremy hated to write in first grade. He would often cry and rebel at the idea of any writing. He enjoyed reading and being read to, but often would interrupt reading to look at the illustrations. If his mother's arm blocked his view of a picture, he would push it out of the way as he preferred to be able to study the illustrations as she read. His first grade teacher used Picturing-Writing elements but chose to focus primarily on the painting phase. In first grade Jeremy seemed to favor art activities because of their hands-on active nature.

During one observation Jeremy fidgeted and squirmed not unlike hundreds of other seven-year-olds. On one occasion, while Jeremy was listening to a story leading to a painting activity he moved from his knees to a prone position. He tapped his fingers and poked his neighbor. Despite this seemingly distracted demeanor, when released to return to his desk he was focused on the assignment and set straight to work. On the first day of observation, Jeremy screamed with pleasure when his teacher announced painting time. Jeremy said: "I am going to paint getting my Christmas tree. It was the tallest one at Home Depot.” At this point Jeremy drew his family and the tree, which he decorated. "This ornament is old; my dad has had it for seventeen years," he says as he points to a spot on the tree. Jeremy's mother reported that he liked Picturing-Writing and it has built confidence in his writing. Even his teacher noticed the increased engagement with writing; since the time she started the project he no longer fought against writing and actually drew and wrote at home. Mrs. P (Teacher): “One thing I noticed, that he's so willing to write now, when we did a brainstorm list of action words for the rain paintings that will become list poems, we brainstormed a list of the words describing happenings in his picture. Most of the kids wanted to know what the minimum number of words, that point never came up for him. Usually he is a minimalist, and will do the bare requirement with other things, he will say, 'I don't do extra so that I can just go play.' This time he really listened to what I said, and he came up and showed me he had a list of 20 words not the minimum of 10 . He was very proud. He didn't balk; it wasn't a chore for him.” 


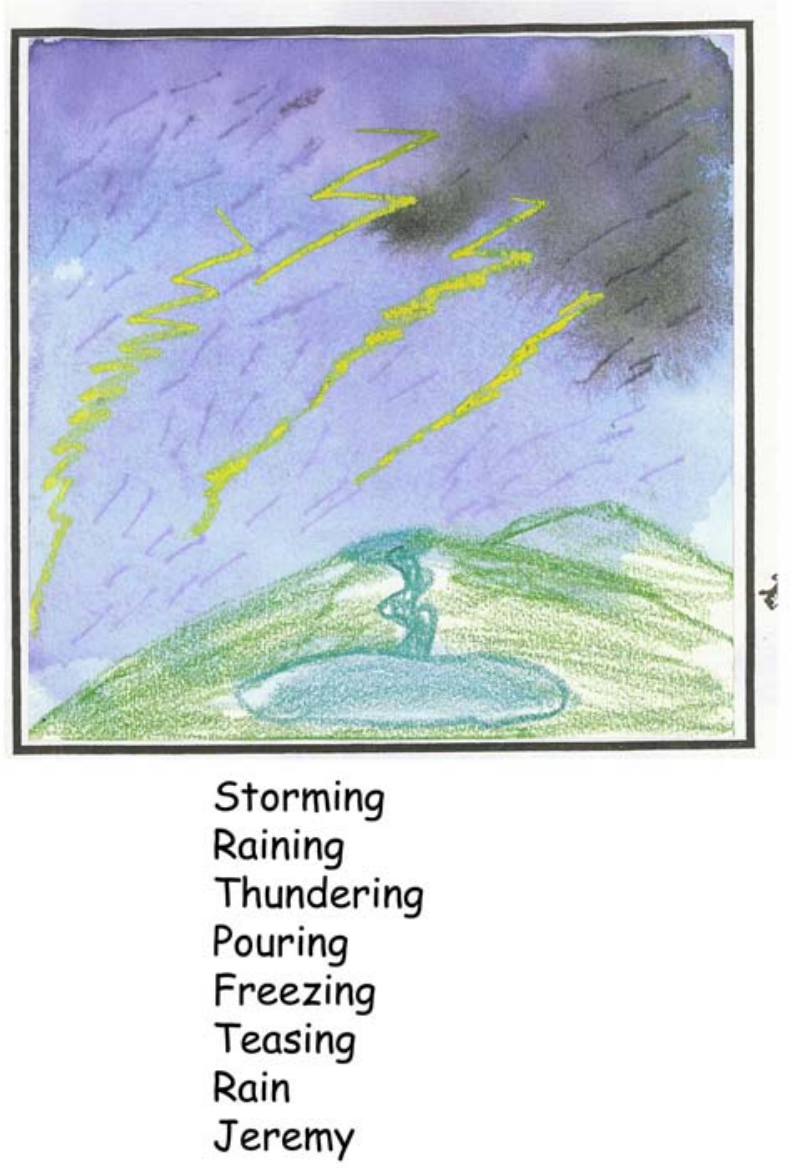

Figure 1

Wendy was not as kinesthetic as Jeremy but still enjoyed the active role of painting. Her paintings showed a level of fine motor control beyond Jeremy's. Both her teacher and mother report that she is enthusiastically involved with Picturing-Writing.

A: "Does she do this at home?"

Wendy's mother: "More last year than this year, we did Picturing-Writing during summer vacation. She goes and paints with grandma sunsets, clouds or a moonlit nights." [Motivational entry point]

In fact when questioned, Wendy reported that she liked painting and preferred to paint first. She found painting motivating and would choose painting as free time activity. All the students in both classrooms who were asked said they found the painting to be a fun activity.

\section{Observation of the world and other art.}

We knew that students were motivated by the opportunity to paint. We further expected to see a rise in their artistic perception, but were somewhat surprised at the intensity of their new found interest in finding colors in the skies and vistas around. During writing, Jeremy intently gazed at his painting, searching the image for ideas and words. He sat hunched over with his chin resting on his cupped hands, focused on his painting on the small easel in front of him. He fidgeted and rocked his chair, but was able to return to the 
painting or the writing at will. In Jeremy's interview we reviewed his previous work. Jeremy discussed the origin of his ideas for the sunrise picture. He remembered a sky he had seen when he and his mom had picked up his cousins.

A: "When did you get the first idea for the painting?"

$\mathrm{J}$ : "When I picked up my cousins in the morning, [...] I saw yellow, blue and pink in the sky in the morning." [Observation of the world: he carries these ideas into the process of painting.]

His mother remarked that his interest and observation of nature had grown considerably since his involvement in Picturing-Writing. Some nights, she said he dragged her outside to look at the night sky describing the moon and stars.

\section{Wendy's Night Tree Poem}

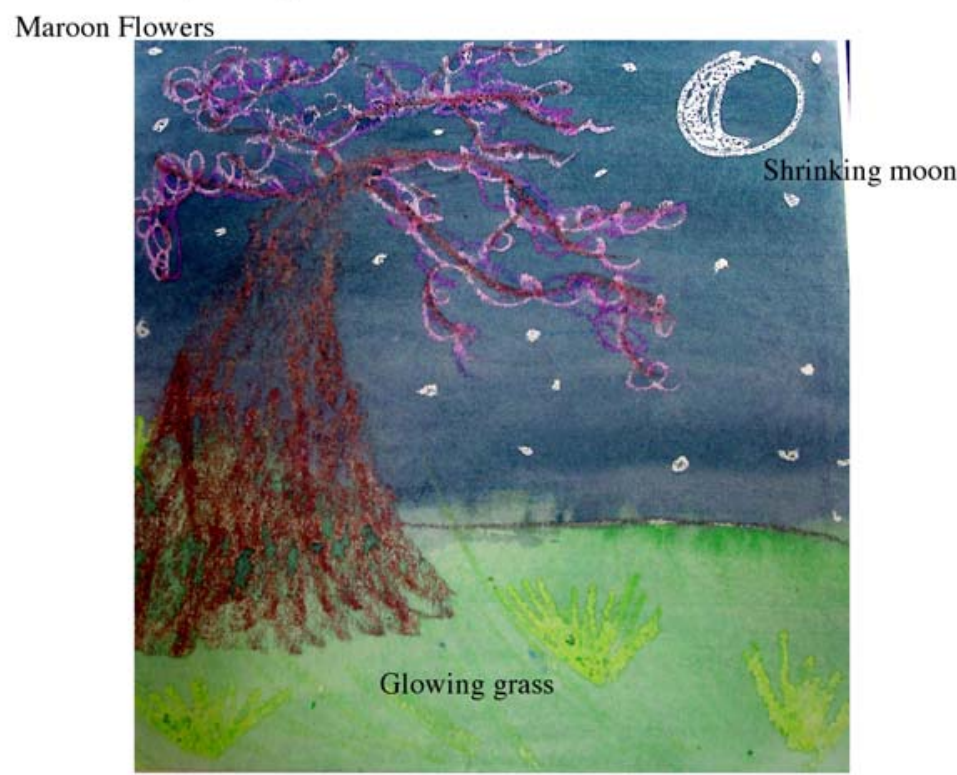

Wendy's Night Poem

Shh!

The calm blue sky is asleep.

Don't wake her up.

The strong tree is wide-awake

While the maroon pink flowers on the big, brown tree

Are whispering secrets to the glowing grass.

The sparkling half moon slowly shrinks,

... so the morning sun can rise.

Figure 2: Night Tree painting and poem 
Wendy, too, showed similar interest in including elements she had observed in nature into her paintings. Her mother reported an increased interest in noticing natural phenomena. She related a story in which Wendy pointed out a sunset and used color words such as vermillion to describe the sky. [Observation of nature]

In Figure 2, Wendy drew a large imposing tree covered in pink lacey blossoms. During the interview process, she was asked to comment on specific pieces of work from their portfolios.

A: "Where did you get the tree?"

W: "At my Grandma's house, I took a walk, there was this really pretty tree and it was tall. It has these purplish-pink leaves and purple flowers." [Observation of nature] She shared how she wanted to include this tree in her painting, so she decided to put the tree in her nighttime painting. The looming size of the tree and the way it dominates the nighttime scene indicates its importance to Wendy. In her poem in Figure 2, she writes: "The strong tree is wide awake while the maroon pink flowers on the big, brown tree are whispering secrets to the glowing grass."

\section{Response to the finished painting}

Since the Picturing-Writing process is based on students' writing about their finished work, it was not unusual to find the students using images from their work to inform their writing. This process must be facilitated so that the students can "mine" their work for new vocabulary or verbal imagery effectively.

Teachers look through their students' portfolios for hints of unusual metaphors or analogies. They then used these budding ideas to enhance the written product, empowering students to trust their creative process. These departures from the usual also provided us insight into the creative process and the link between the visual and the written. Jeremy provided an interesting verbal description of a tree looking like a broom sweeping the sky (Figure 3).

J: [reads his work ending with] "The tree looks like a broom."

Mrs. P: "Yes, it does look like a broom."

J: "That's because it is sweeping the sky." [Response to painting]

Mrs. P: "You should put that in your story, that's a good thing."

Wendy took pleasure in sharing her work. Both in the observation and interview, she demonstrated a keen reliance on the image for her writing. It was during the interview that Wendy's use of the painted image as a pre-writing tool was clearly evident. In this interview we used her Picturing-Writing portfolio to guide my questions and her responses (refer to Figure 4).

A: "Why did you think the seaweed was like a snake?"

W: "Well, snakes are wiggly."

A: "Hmm, sizzling ocean (direct quote), where did you get that idea?"

W: "You can see there are bubbles." [Shows me the bubbles in her picture, which is from the interaction of salt and watercolor.]

A: "So you wrote: 'Crackling, clouds were lazy, "Why did you think of lazy?"

W: "It kind of looks like calm and I thought of sleepy and stuff." [Response to the image] 


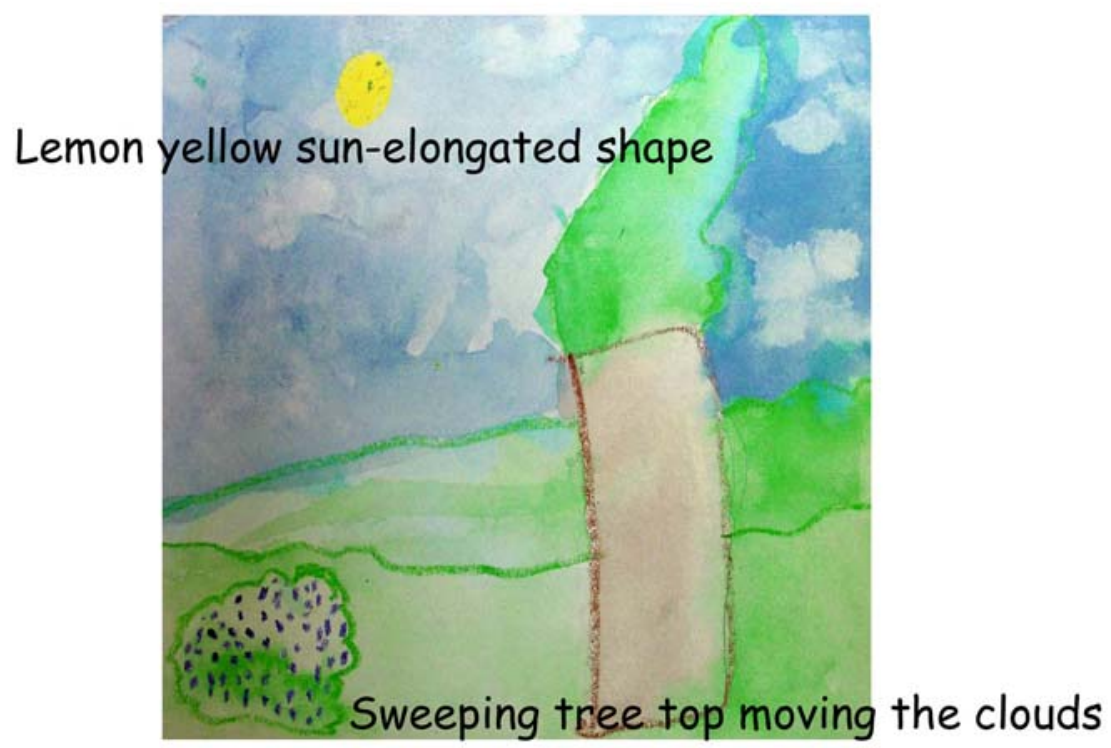

The sun looks like a lemon.

It is cool because it is yellow.

The bush looks like a bumpy bunny.

The sun and clouds are playing hide-and-go seek.

The tree looks like a broom. It sweeps the sky.

Jeremy

Figure 3: Jeremy's Broom Tree painting and poem

Watercolor, especially the wet into wet technique, allows colors to run, blossom and mix, creating "happy accidents." These accidents allowed the students a level of spontaneity that crayon or pencil drawings usually don't encourage. Wendy was able to discover and use those happy accidents. One such use was her twilight piece. She writes: "The gentle, soft pink, puffy sky eats its cotton candy self." When asked where she got the idea, she showed how the pink paint of the mountains had diffused into the sky, resembling cotton candy. In the phrase, "Brilliant, sizzling bubbles play underwater hopscotch with the glowing seaweed" (Figure 4), the bubbles had reminded her of boiling or sizzling water. While her original concept did not include those ideas, the painting acts provided new complexities embedded in reality. Wendy is then able to describe the newly observed reality with complex simile language, as she says, "It's easier to write when you look at something."

Jeremy's teacher was the first at her site to be actively involved with Picturing-Writing, but honestly reflects that she had never really considered how the students interacted with their paintings beyond using them to motivate and engage students in the writing process. In her interview she reflected that she assumed the paintings tended to be illustrative of student ideas. She noticed that the painting process motivates especially in Jeremy's case, which was 
often willing to keep painting until she stopped him. The fact that the paintings themselves gave rise to new verbal images was something she found worth considering.

Mrs. P: "He is more tied to an image when he gets stuck, sometimes he will get a hint of a character from something in the painting. Then I think he and the others find it easier to have images to write from. I know I can draw them back to the image and it makes it easier to keep them focused on the topic."

At the same time, Jeremy struggled with fine motor control, his writing wandered off the lines or out of boxes. She felt that the spontaneity and loss of control offered by the watercolor techniques and crayon resist allowed Jeremy to succeed. The spontaneity and freedom of wet into wet watercolor gave the paintings an abstract quality that allowed Jeremy the opportunity to find numerous objects to discuss and finally write about.

For Jeremy, the painting first allowed him to enter the writing process through the kinesthetic activity of painting. The resultant images on the paper gave him a focal point to find descriptive subjects leading to richer written products. He combined imaginary situations while often the image was based on first person experiences.

We also questioned Wendy's teacher about the process in her classroom. She shared that she had just asked the students to write what they had learned from PicturingWriting. Their responses gave a glimpse into ways that students used the image. Wendy wrote, "I learned that 'silver dollar words' (descriptive specific strong words) make your writing stronger and more interesting."

Thus in both cases, the paintings provided both stimuli for student writing and anchors for focus. The finished product might resemble their original concept such as the giant flowering tree or it may have changed and gained new dimensions.

\section{The creative process or While I was doing the art.}

From anecdotal observations, we expected to find that the art making process itself was engaging to students. For years we have seen the joy students receive from the act of painting. At times they would literally paint through the paper, mesmerized by the sheer act of washing color upon color. A recurring observation was that students were getting new writing ideas while creating art. Students demonstrated the ability to react and elaborate on ideas during the actual painting. Often new ideas or variations emerged virtually in midbrush stroke.

Jeremy described his daytime picture, Figure 3, as a sun yellow like a lemon and powering up. In the interview Jeremy referred several times to unique image features. In one example he created a "melting sun" a creative "accident" that occurs often unintentionally when watercolors are used in painting.

J: [Reads another section of his writing] "It looks like a lemon."

A: "Why did you pick lemon?"

J: "Because [Gestures with hands] it's big and round and looks like a lemon. [Reads next section] It is melting."

A: "Why did you think about melting, because the sun ..."

$\mathrm{J}$ : "Because there is a little thing right here." [Creative process: Points to runny spot on painting below his sun. This section seems to be a section in which the idea occurred to him during the painting process.]

It was obvious that Jeremy approached the painting process with gusto and used the "happy accidents of watercolor' as a fertile image field for writing.

A: "Ok, read the first part." 
J: "The blazing fiery hot sun sets. The sun lights up the sky." [Reads his written words.] "It is cool because it is mixing with the red sky." [Creative process-the wet into wet watercolor process in which colors bleed into each other.]

A: "Have you ever seen a sunset that looks like your sunset?"

$\mathrm{J}$ : "When I was like four years old, in the same place but not the same house, I could see up the field to the mountains and it was a lot red." [Observation of the world and then elaborated on during the painting process.]

The painting process seemed to give Wendy time to formulate richer ideas and schemas. In her night picture, as seen in Figure 2, she assembled objects from different places and times to create a new image. When she drew the moon, she drew a full circle first and decided to fill in only the crescent. She then used the image to pull new ideas for her writing indicating that she originally intended it to be a full moon, but decided to change it to a crescent moon. When she added the watercolor wash, the original full circle appeared. Wendy commented that the moon she had created it seemed to be shrinking, so she added this idea to her poem [Creative process]. Poem phrases that emerged directly from the painting were the blue-black sky, the glowing grass (the yellow green is contrasted with the dark), and the sparkling moon is shrinking (crayon resist in a dark sky and full circle with crescent colored.)

\section{Wendy's Ocean Painting}

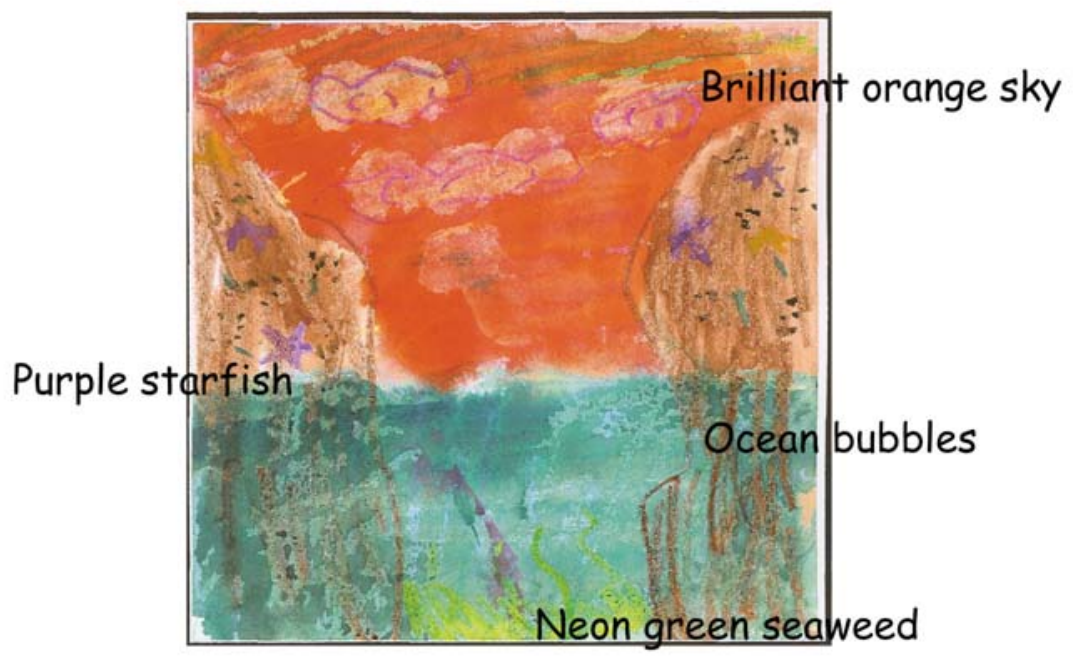

The silent freezing clouds are leaping over the hot orange sky. The splashing turquoise blue water is madly knocking down the cracking five-sided starfish. The brilliant sizzling bubbles are swaying the glowing seaweed as they gently slither through it.

Wendy

Figure 4: Wendy's ocean painting and poem 
At the same time active moving shapes and lines dominated Wendy's work. She employed color in abundance, often using arbitrary color choice. In her seaside picture, she used purple for the starfish and a brilliant orange sky with many colors of both crayon and paint. We inquired how she created her seascape, Figure 4.

W: "I didn't have any ideas, but then I thought back to Mrs. P's class, she made this really pretty picture with two rocks and the water, and I wanted to make a picture like that so I started out, with rocks and the seaweed." [Creative process: Note the elaboration.]

W: (smiles)-“Yeah, so then it wasn't very bright," [Mrs. P's picture was a dark nighttime picture] "so I thought I would do the opposite, I would put every color in the sky with my crayon, then I mixed red and orange together." [Creative process: refers to the painting process].

When we reviewed her picture of a landscape with a sunset and a small pond reflecting the sky, we asked whether she had planned to create the reflections.

A: "When you put the orange in here, did you think about having the pond reflect or was that a happy accident?"

W: "I did that; it's not an accident." [Creative process: direct indication of the painting process and instruction, as part of the elaboration of thought.]

She then used what she thought about later in her writing. In many cases, both Wendy and Jeremy created works with ideas that they carried into the process, but through the gift of time were allowed to elaborate or evolve those ideas further. This provided them with writing that was far richer than their original concepts.

\section{Conclusion}

The four categories validated in this study are connected in two ways. The categories can be seen as a reflection of the instructional sequence. Starting with a motivational entrypoint, students then observe the world, employ the creative process and finally respond to the finished work. The sequence may seem a trivial element, but in fact it is critical- the benefits of using robust art emerge only when the sequence is followed and the art making precedes the writing. The four categories can also be seen as steps that maximize cognitive engagement. The richness of the writing then, is a result of the art providing meaningful contextualized cognitive engagement.

A brush floats across the damp paper, the paint swirls out creating whorls and blossoms of deep blue mixed with violet. The child's dots of white crayon appear as stars in the night sky. Crayon lines create branches that zigzag across this sky and mysterious pink blossoms glow in the fading moonlight. The child is creating symbols representing a synthesis of experiences and creating new ones. Writing is integrated with art, equal partners in creating meaning. The fading moon is night turning into day; the wavy green lines are grasses blowing in the night breezes. At the same time the child is composing a story, she is creating a fusion of ideas in paint and words, which later are transferred to text.

It is a uniquely human endeavor to use visual images to communicate. Animals of all species may use vocal sounds to communicate, but only human beings uses visual imagery to accent the spoken and written word. Dyson (1986) proposed that children use art as concrete symbol representation that mediates between object and representation in writing. Smagorinsky (1993) furthers this idea that art can function as a non-linguistic compositional 
tool, not as part of the development process. We propose that it is this connection of visual and verbal imagery helps students increase their ability to express their ideas and thoughts. It can serve as a symbol system to communicate ideas, it can organize and stimulate thinking, and it can contribute to the elaboration of thought.

Visual art is more, however, than the creative process. An important element of a visual arts program is the development of skill and aesthetic perception. During this process of looking and replicating the world around, students discover that they see the world in new ways. Often they see new colors or shadows they had never noticed before. This heightened perception is an important step in the visual art making process.

The model of art integration is viewed in this study as a triangle between the child and the creative process and the artwork, itself. We propose that the child creates and during the act of creation is involved in elaborative thought as suggested by Eisner (2002) and Efland (2002). The artwork also serves a cognitive stimulus. Children make associations with the finished work based on unintended elements that appear in the art. For example, in watercolor, the paint takes on its own agency in the painting process and the finished painting may suggest ideas that the child previously had not considered. The finished product then is re-represented in written communication. The art plays a critical role as a mediating event for the compositional process (Trainin, Andrzejczak, \& Poldberg, 2005).

In the context of this paper, we would suggest future research would examine the efficacy with different ages of students. Research should focus on the benefits for special education and English language learners.

\section{Educational Implications}

In traditional classroom settings, teachers often have the students illustrate stories or essays. This illustration process is often used as a motivational device to induce the students to do the original writing assignment most often happening after the writing is done.

Paradoxically this approach motivates students to write less so they can get to the art, and at the same time the art creation is constrained by the writing instead of enriching it. This standard approach captures only a small portion of the potential benefit we uncovered in our study. Through the imaging of the event or place, the student creates a mental picture and then attempts to reproduce it on paper with the result that the student's ideas are reproduced in a concrete form. Simultaneously the media interact with student's original intent layering new dimensions created by the physicality of paint on paper, shifting the paradigm of the original idea.

The order reversal of art creation first, then writing, results in a rich metaphoric language and sensory detail through the child's engagement with their images that exists both in paint and thought. The creative process allows children a freer base of expression as they are not constrained by the words that they can spell or the vocabulary they know.

Based on this study we suggest that the teachers take the time to introduce media skills, art vocabulary, and aesthetic perception to avoid the art production becoming an afterthought, a quick sketch of crayon with stick figures and hastily drawn landscapes. We believe that the cognitive benefits in the creation of robust artworks are worth the time and effort. Through paint and crayon, students can create worlds full of texture and colors, inhabited by creatures of imagination and dreams. Then, facilitated by the teacher, they can make their own connections between image and text. 


\section{Note}

This project was part of Project RAISE that was funded by the US Department of

Education, Arts Model Program Development and Dissemination Grant, \# S351D010148

We would like to thank our editors and reviewers for their support and critical suggestions.

\section{References}

Burger, K., \& Winner, E. (2000). Instruction in Visual Art: Can It Help Children Learn to Read? Journal of Aesthetic Education, 34(3-4), 277-293.

Cho, M. M. (1996, March 1996). Using Visual Art to Motivate At-Risk Children. Teaching Pre K-8, 26, 54-55.

Dyson, A. H. (1986). Transitions and Tensions: Interrelationship between the Drawing, Talking and Dictating of Young Children. Research in the Teaching of English, 20(4), 379409.

Dyson, A. H. (1987). Individual Differences in Beginning Composing: An Orchestral Vision of Learning to Compose. Written Communication, 9(9), 411-442.

Dyson, A. H. (1988). Negotiating among Multiple Worlds: The Space/Time Dimensions of Young Children's Composing. Research in the Teaching of English, 22(4), 355-390.

Eisner, E. W. (2002). The Arts and the Creation of Mind. New Haven, CT: Yale University Press.

Ernst, K. (1994). Picturing Learning. Portsmouth, NH: Heinemann.

Olshansky, B. (1990). Portfolio of Illustrated Step-by-Step Art Projects for Young Children. West Nyack, New York: The Center for Applied Research in Education, Business and Professional Division.

Olshansky, B. (1994). Making writing a work a work of art: Image-making within the writing process. Language Arts, 71, 350-356.

Olshansky, B. (1995). Picture this: An arts-based literacy. Educational Leadership, 53, 44-47.

Olshansky, B. (1998). Evaluation of a Year-Long Art and Literature-Based Approach to Writing: University of New Hampshire.

Sadoski, M., \& Paivio, A. (1994). A Dual Coding View of Imagery and Verbal Processes in Reading Comprehension. In R. B. Ruddell, M. R. Ruddell \& H. Singer (Eds.), Theoretical Models and Processes of Reading, 4th Edition (pp. 582-601). Newark, DE: International Reading Association.

Sigel, I. E. (1970). The distancing hypothesis: A causal hypothesis for the acquisition of representational thought. In M. R. Jones (Ed.), Miami symposium on the prediction of behavior, 1968: Effect of early experiences (pp. 99-118). Coral Gales, FL: University of Miami Press.

Smagorinsky, P. (1997). Artistic composing as representational process. Journal of Applied Developmental Psychology, 18, 87-105.

Smagorinsky, P., \& Coppock, J. (1993). Broadening the Notion of Text: An Exploration of an Artistic Composing Process. Paper presented at the American Educational Research Association, Atlanta, GA.

Smagorinsky, P., \& Coppock, J. (1994). Cultural Tools and the Classroom Context: An Exploration of an Artistic Response to Literature. Written Communication, 11(3), 283310.

Strauss, A., \& Corbin, J. (1990). Basics of qualitative research: Grounded theory procedures and techniques. Thousand Oaks, CA: Sage. 
Tishman, S., MacGillivray, D., \& Palmer, P. (1999). Investigating the Educational Impact and Potential of Museum of Modern Art Visual Thinking Curriculum: Final Report (Unpublished report). New York, New York: Museum of Modern Art.

Trainin, G., Andrzejczak, N., \& Poldberg, M. (2005). Art and Writing a Mutually Beneficial Relationship. Arts and Learning Research Journal, 2(1), 139-155.

Valentine, J. C., DuBois, D. L., \& Cooper, H. (2004). The Relation Between Self-Beliefs and Academic Achievement: A Meta-Analytic Review. Education Psychologist, 39(2), 11-133.

Vygotsky, L. S. (1978). Mind in Society. Cambridge: Harvard University Press.

Wilhelm, J. (1995). Reading is Seeing: Using Visual Response to Improve the Literary Reading of Reluctant. Journal of Reading Behavior, 27(4), 467-502.

Winner, E., \& Cooper, M. (2000). Mute Those Claims: No Evidence (Yet) for a Causal Link between Arts Study and Academic Achievement. Journal of Aesthetic Education, 34(3-4), $11-75$.

Winner, E., \& Hetland, L. (2000). The Arts in Education: Evaluating the Evidence for a Causal Link. Journal of Aesthetic Education, 34(3-4), 3-10.

\section{About the Authors}

Nancy Andrzejczak is currently the grant writer for the Lake Elsinore Unified School District (LEUSD). She just completed four years as the director of Project RAISE with LEUSD and was named the "California Art Educator of the Year" at the 2005 National Art Education Association annual conference. She is now in her fourth year of doctoral studies at University of California, Riverside, in Instructional Leadership and Policy, emphasizing policies affecting teacher practice and art education.

Dr. Guy Trainin is an Assistant Professor of Literacy at University of Nebraska, Lincoln. He focuses his research in the area of reading acquisition, art and literacy integration and research methods. In the past six years, he has been responsible for analyses related to a series of design experiments in early reading acquisition. Dr. Trainin teaches graduate courses in literacy and research methods. He is currently serving as an external evaluator to the Nebraska Reading First grant and Project RAISE. He is conducting research using quantitative approaches focusing on Latent and Hierarchical Linear Models.

Monique Poldberg was named as the "Outstanding Elementary Art Educator of the Year" for the California Art Education Association. She teaches in the Lake Elsinore Unified School District (LEUSD), Lake Elsinore, California. She played a key role in the research and dissemination for the previous VIEW project and was a Distant VIEW pilot teacher. As an active practitioner she is able to bridge the gap between research theory and practice, adding to the project the perspective of an active classroom teacher and researcher. 


\section{International Journal of Education \& the Arts}

\begin{tabular}{|c|c|}
\hline & $\begin{array}{c}\text { Editors } \\
\text { Tom Barone } \\
\text { Arizona State University, U.S.A }\end{array}$ \\
\hline \multicolumn{2}{|c|}{$\begin{array}{l}\text { Liora Bresler } \\
\text { University of Illinois at Urbana-Champaign, U.S.A. }\end{array}$} \\
\hline & $\begin{array}{l}\text { Executive Editor } \\
\text { Gene V Glass } \\
\text { Arizona State University, U.S.A. }\end{array}$ \\
\hline Un & $\begin{array}{c}\text { Associate Editors } \\
\text { Laurel Campbell } \\
\text { esity of Illinois at Urbana-Champaign, U.S.A. }\end{array}$ \\
\hline & $\begin{array}{c}\text { Jason Helfer } \\
\text { Millikin University, U.S.A. }\end{array}$ \\
\hline \multicolumn{2}{|c|}{$\begin{array}{c}\text { Regina Murphy (2002-2004) } \\
\text { St. Patrick's College, Dublin City University, Ireland }\end{array}$} \\
\hline \multicolumn{2}{|c|}{$\begin{array}{l}\text { Tracie Costantino (2000-2004) } \\
\text { University of Illinois at Urbana-Champaign, U.S.A. }\end{array}$} \\
\hline \multicolumn{2}{|r|}{$\begin{array}{l}\text { Alyson Whyte (2002-2004) } \\
\text { Auburn University, U.S.A. }\end{array}$} \\
\hline \multicolumn{2}{|r|}{ Editorial Board } \\
\hline Peter F. Abbs & University of Sussex, U.K. \\
\hline Eunice Boardman & University of Illinois at Urbana-Champaign, U.S.A. \\
\hline Norman Denzin & University of Illinois at Urbana-Champaign, U.S.A. \\
\hline Kieran Egan & Simon Fraser University, Canada \\
\hline Elliot Eisner & Stanford University, U.S.A. \\
\hline Magne Espeland & Stord/Haugesund University College, Norway \\
\hline Gary McPherson & University of New South Wales, Australia \\
\hline Robert Stake & University of Illinois at Urbana-Champaign, U.S.A. \\
\hline Susan Stinson & University of North Carolina-Greensboro, U.S.A. \\
\hline Christine Thompson & Pennsylvania State University, U.S.A. \\
\hline Peter Webster & Northwestern University, U.S.A. \\
\hline
\end{tabular}

